\title{
Perbandingan Status Fungsional pada Pasien Nyeri Punggung Bawah Akut Non-Spesifik yang Diberikan Kombinasi Ibuprofen dan Eperison versus Ibuprofen
}

\author{
Raven C. P. Maubanu, ${ }^{1}$ Rizaldy T. Pinzon, ${ }^{2}$ M. M. A. Dewi Lestari ${ }^{1}$
}

\author{
${ }^{1}$ Fakultas Kedokteran Universitas Kristen Duta Wacana, Yogyakarta, Indonesia \\ ${ }^{2}$ Rumah Sakit Bethesda, Yogyakarta, Indonesia \\ Email: RavenC97@gmail.com
}

\begin{abstract}
There are several types of medications that can be used to relieve pain in low back pain (LBP) cases, inter alia non-steroidal anti-inflammatory drugs (NSAIDs), opioids, non-opioid analgesics, antidepressants, and muscle relaxants. This study was aimed to compare the functional status of patients treated with combination of ibuprofen and eperisone hydrochloride and those treated with ibuprofen only. This was a randomized controlled trial. Samples were taken by using purposive sampling with a total of 100 samples as subjects, divided into two groups: group 1 as the experimental group treated with combination therapies of ibuprofen and eperisone hydrochloride and group 2 as the control group treated with ibuprofen only. The therapy was performed for three times with a span of two weeks between each visit. The functional status was measured with fingerto-floor distance (FFD) test and the analysis was performed by using the chi-square test. The results showed 39 males and 61 females as subjects. There was no meaningful difference on the basic characteristics. The functional status of the subjects improved as the intensity of pain decreased. The results of the FFD test indicated that there was improvement of functional status of each group on the second visit, as follows: group 1 had 30 subjects (62.5\%) with a distance of $<10 \mathrm{~cm}$ and group 2 had 24 subjects $(55.8 \%)$ with a distance of $<10 \mathrm{~cm}$. In conclusion, the functional status of nonspecific acute lower back pain patients treated with combination of ibuprofen and eperisone hydrochloride was better than those treated with ibuprofen only.
\end{abstract}

Keywords: low back pain; functional status; ibuprofen; eperisone hydrochloride combination

\begin{abstract}
Abstrak: Terdapat beberapa jenis obat yang dapat digunakan untuk menghilangkan nyeri pada nyeri punggung bawah (NPB), antara lain golongan obat anti inflamasi non steroid (OAINS), opioid, analgesik non-opioid, antidepresan, dan pelemas otot. Hasil penelitian menunjukkan bahwa OAINS tidak cukup memadai sehingga perlu tambahan pelemas otot. Penelitian ini bertujuan untuk mendapatkan perbandingan status fungsional pasien yang diberikan terapi kombinasi ibuprofen dan eperison dengan yang diberikan terapi ibuprofen saja. Penelitian ini menggunakan randomized controlled trial. Sampel diambil menggunakan purposive sampling dengan total 100 sampel sebagai subjek. Subjek dibagi menjadi dua kelompok, yaitu kelompok 1 sebagai kelompok eksperimental yang diberikan terapi kombinasi ibuprofen dan eperison dan kelompok 2 sebagai kelompok pembanding yang diberikan terapi ibuprofen. Terapi dilakukan sebanyak 3 (tiga) kali dengan rentang waktu dua minggu antara setiap kunjungan. Status fungsional diukur dengan finger-to-floor distance test (FFD). Data penelitian dianalisis dengan uji chi-square. Hasil penelitian mendapatkan 39 lakilaki dan 61 perempuan sebagai subyek penelitian. Tidak terdapat perbedaan bermakna pada karakteristik dasar. Status fungsional subjek semakin membaik bila intensitas nyeri semakin berkurang. Hasil FFD test menunjukkan adanya perbaikan status fungsional setiap kelompok pada kunjungan kedua, yaitu pada kelompok 1 terdapat 30 subjek $(62,5 \%)$ yang memiliki jarak $<10 \mathrm{~cm}$ dan pada kelompok 2 terdapat 24 subjek $(55,8 \%)$ yang memiliki jarak $<10 \mathrm{~cm}$. Simpulan penelitian ini ialah status fungsional pada pasien NPB akut non-spesifik yang diberikan pengobatan terapi kombinasi ibuprofen dan eperison lebih baik daripada yang diberikan pengobatan ibuprofen saja.

Kata kunci: nyeri punggung bawah; status fungsional; ibuprofen; eperison
\end{abstract}




\section{PENDAHULUAN}

Nyeri punggung bawah (NPB) atau low back pain (LBP) merupakan gangguan muskuloskeletal pada daerah lumbal atau lumbosakral yang umum terjadi pada orang dewasa. ${ }^{1}$ Nyeri yang ditimbulkan dapat berupa rasa tertekan benda tumpul, tertusuk, atau terbakar, dan pada kategori tertentu membutuhkan adanya terapi invasif. Walaupun tidak menyebabkan kematian namun NPB dapat menjadi beban bagi individu tersebut. $^{2}$

Prevalensi terjadinya NPB di dunia ialah $9,17 \% .^{2}$ Berdasarkan data Riskesdas 2018 , cedera yang terjadi pada punggung sebanyak 6,5\%. ${ }^{3}$ Di Indonesia, masih belum terdapat data yang menunjukkan angka kejadian pada pasien NPB. Meskipun demikian, orang dewasa yang berusia sekitar 3555 tahun memiliki risiko terkena NPB. Diperkirakan orang dewasa yang tinggal di Jawa Tengah berusia 65 tahun atau sekitar $40 \%$ penduduk usia dewasa pernah mengalami NPB dengan prevalensi pada laki-laki sebesar $18,2 \%$ dan perempuan $13,6 \%$. Pada orang dewasa yang mengalami NPB, terdapat setidaknya satu diantara 20 yang mengalami serangan NPB akut dan harus dirawat di rumah sakit. ${ }^{4}$ Studi empirik tentang NPB oleh Tsekoura et $\mathrm{al}^{5}$ di Greek menyatakan bahwa setidaknya lebih dari $84 \%$ perawat yang mengikuti penelitian ini pernah merasakan NPB sekurang-kurangnya sekali dalam hidupnya.

Terdapat beberapa faktor risiko yang menyebabkan NPB, yaitu antara lain usia, indeks massa tubuh (IMT), lamanya bekerja, kursi untuk melakukan pekerjaan, posisi duduk, dan kebiasaan olahraga. ${ }^{6}$

Dalam mengurangi rasa nyeri pada punggung bawah, umumnya pasien akan diberikan beberapa jenis obat. Terdapat beberapa golongan obat yang dapat digunakan untuk mengobati atau mengurangi rasa nyeri, antara lain obat golongan obat anti inflamasi non-steroid (OAINS), opioid, analgesik non opioid, antikonsulvan, antidepresan, dan pelemas otot (muscle relaxant).$^{7-9}$ Hasil penelitian menunjukkan bahwa bila NSAID tidak cukup memadai dalam mengurangi nyeri yang dirasakan dapat diberi tambahan muscle relaxant. ${ }^{10}$ Obat-obatan yang dapat mengurangi rasa nyeri dan kekakuan otot pada jenis muscle relaxant antara lain ialah eperison yang dapat mengurangi rasa nyeri dan tegang pada otot yang mengalami nyeri, terutama pada nyeri punggung bawah. ${ }^{7-9}$ Menurut penelitian yang telah dilakukan oleh Van et al, muscle relaxant mampu memberikan efektifitas yang lebih baik dalam menangani NPB bila dibandingkan dengan plasebo. ${ }^{7}$

Dalam mengukur status fungsional pada pasien NPB akut, terdapat beberapa macam pengukuran yang digunakan, salah satunya ialah finger-to-floor-distance (FFD) test. Menurut Haywood et al, ${ }^{11}$ tes FFD adalah tes jarak antara ujung jari tengah dan kanan setelah fleksi lumbar maksimal, sembari mempertahankan eksistensi lutut. Jarak yang lebih kecil menunjukkan gerakan/kelenturan yang baik dan diukur dengan tali pita. Hasil akan dikatakan normal apabila ujung jari tengah pasien berjarak $10 \mathrm{~cm}$ dari lantai. ${ }^{12}$

\section{METODE PENELITIAN}

Penelitian ini menggunakan metode randomized controlled trial (RCT). Desain studi penelitian ini terdiri atas 2 (dua) kelompok yaitu, kelompok eksperimental diberikan kombinasi ibuprofen $400 \mathrm{mg}$ dan eperison $50 \mathrm{mg}$ sebagai terapi dan kelompok pembanding diberikan ibuprofen $400 \mathrm{mg}$. Pengambilan sampel menggunakan purposive sampling dengan total 100 sampel.

Subjek penelitian ini berjumlah 100 pasien. Dari total subjek tersebut, 54 subjek masuk pada kelompok eksperimental dan 46 subjek pada kelompok pembanding. Penelitian dilakukan selama 4 (empat) minggu sejak kunjungan pertama pasien berobat. Pengambilan data dilakukan sebanyak 3 (tiga) kali, yakni dari baseline dan setelah menjalani terapi setiap 2 (dua) minggu. Selama terapi diberikan, subjek diukur tingkat pengurangan nyerinya menggunakan numeric pain scale dan menggunakan FFD test untuk melihat perbaikan status fungsional subjek pada masing-masing kelompok. Data dianalisis menggunakan uji MannWhitney.

Penelitian yang dilakukan telah ter- 
daftar pada Register Penelitian Litbangkes dengan judul ' A comparison between nonsteroid anti inflammatory drugs and its combination with eperisone hydrochloride in patient with acute non-specific back pain with muscle spasm' dan telah mendapatkan kelayakan etik dari Komite Etik Penelitian Kesehatan Fakultas Kedokteran Universitas Kristen Duta Wacana dengan nomor kelaikan etik: 1141/C/16/FK/2020.

\section{HASIL PENELITIAN}

Jumlah subjek pada penelitian ini sebanyak 100 orang yang dibagi menjadi dua kelompok, masing-masing 54 subjek pada kelompok eksperimental dan 46 subjek pada kelompok pembanding. Subjek melakukan tiga kali kunjungan, dimulai dari baseline, kunjungan kedua, dan kunjungan ketiga. Tabel 1 memperlihatkan karakteristik dasar subjek penelitian. Perempuan memiliki jumlah lebih banyak daripada lakilaki. Usia rerata subjek pada kelompok eksperimental $51,67 \pm 14,235$ tahun sedangkan pada kelompok pembanding ialah $53,96 \pm 14,035$ tahun dan tidak menunjukkan adanya perbedaan bermakna.

Pada penelitian ini intensitas nyeri diukur dengan menggunakan numeric pain scale. Hasil penelitian mendapatkan bahwa pada kunjungan pertama, rerata nyeri pada

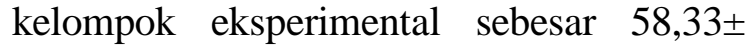
20,25 dan pada kelompok pembanding sebesar 56,52 $\pm 21,31$. Pada kunjungan kedua, didapatkan intensitas penurunan nyeri yang lebih baik pada kelompok eksperimental $(28,13 \pm 24,72)$ dibandingkan kelompok pembanding $(34,42 \pm 28,47)$. Kunjungan ketiga juga menunjukkan kelompok eksperimental mengalami penurunan nyeri yang lebih baik $(20,34 \pm 23,82)$ dibanding kelompok pembanding $(28,71 \pm 20,12)$.

Gambar 1 memperlihatkan penurunan nyeri yang lebih besar terdapat pada kelompok 1 bila dibandingkan kelompok 2 .

Tabel 1. Karakteristik dasar subjek

\begin{tabular}{|c|c|c|c|c|c|c|}
\hline \multicolumn{2}{|c|}{ Karakteristik subjek } & $\begin{array}{c}\text { Kelompok } 1 \\
\text { (Ibuprofen }+ \\
\text { Eperisone) } \\
(\mathbf{n}=\mathbf{5 4}) \\
\end{array}$ & $\%$ & $\begin{array}{l}\text { Kelompok } 2 \\
\text { Ibuprofen } \\
(n=46)\end{array}$ & $\%$ & $\mathbf{p}$ \\
\hline \multirow{2}{*}{ Jenis kelamin } & Laki-laki & 22 & 40,7 & 17 & 37 & \multirow{2}{*}{0,856} \\
\hline & Perempuan & 32 & 59,3 & 29 & 63 & \\
\hline \multicolumn{2}{|c|}{ Usia rerata $\pm \mathrm{SD}$} & $51,67 \pm 14,235$ & & $53,96 \pm 14,035$ & & 0,453 \\
\hline \multirow[t]{7}{*}{ Komorbiditas } & $\mathrm{Ya}$ & 28 & 51,9 & 23 & 50,0 & \\
\hline & Tidak & 26 & 48,1 & 23 & 50,0 & \\
\hline & Hipertensi & 13 & 25,0 & 12 & 26,1 & \\
\hline & Diabetes melitus & 11 & 20,4 & 4 & 8,7 & 1,000 \\
\hline & Penyakit kardiovaskular & 0 & 0 & 2 & 4,3 & \\
\hline & Penyakit gastrointestinal & 13 & 24,1 & 10 & 21,7 & \\
\hline & Lain-lain & 0 & 0 & 0 & 0 & \\
\hline \multirow[t]{9}{*}{ Komedikasi } & $\mathrm{Ya}$ & 51 & 94,4 & 42 & 91,3 & \\
\hline & Tidak & 3 & 5,6 & 4 & 8,7 & \\
\hline & Obat anti-hipertensi & 11 & 20,4 & 10 & 21,7 & \\
\hline & Obat anti-diabetes & 11 & 20,4 & 4 & 8,7 & \\
\hline & Obat anti-platelet & 1 & 1,9 & 4 & 8,7 & 0,856 \\
\hline & PPI/H2 Blocker & 47 & 87,0 & 36 & 78,3 & \\
\hline & Vitamin & 9 & 16,7 & 8 & 17,4 & \\
\hline & Steroid & 29 & 53,7 & 32 & 69,6 & \\
\hline & Lainnya & 1 & 1,9 & 1 & 2,2 & \\
\hline
\end{tabular}




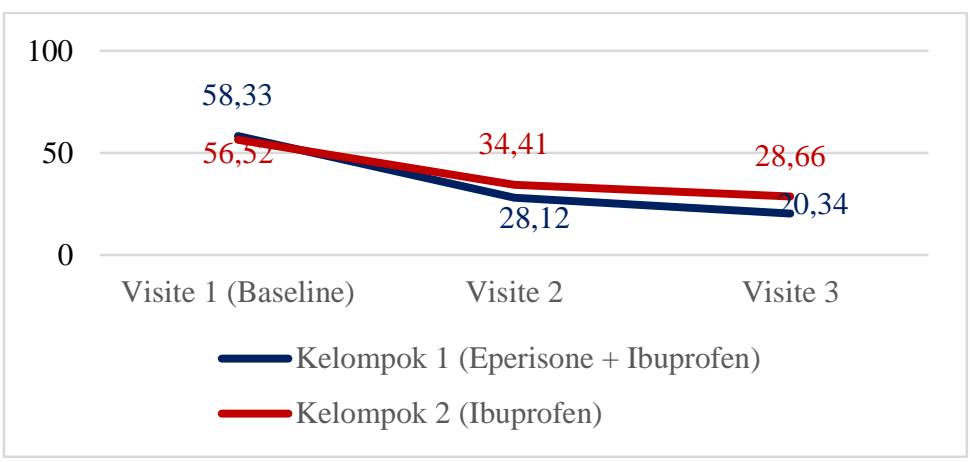

Gambar 1. Grafik penurunan nyeri antara kedua kelompok pada kunjungan/visite I, II, dan III

Pemulihan nyeri sebesar $>30 \%$ pada kunjungan kedua lebih banyak dirasakan pada subjek kelompok ekperimental dengan 39 subjek $(81,3 \%)$ dibandingkan kelompok pembanding, yakni 29 subjek $(67,4 \%)$. Hasil uji statistik mendapatkan adanya nilai $\mathrm{p}$ yang bermakna $(\mathrm{p}=0,132<0,05)$. Pada kunjungan ketiga, pemulihan nyeri $>50 \%$ juga lebih banyak dijumpai pada subjek kelompok eksperimental dibandingkan kelompok pembanding, yakni antara $72,4 \%$ dengan $46,7 \%$. Hasil statistik menunjukkan adanya nilai $p$ yang bermakna $(\mathrm{p}=0,046<0,05)$.

Subjek pada penelitian ini juga diberikan rescue medication berupa parasetamol dengan dosis $500 \mathrm{mg}$. Rescue medication diberikan sebanyak maksimal 10 tablet setiap kunjungan dan dikonsumsi apabila subjek tidak mampu mentoleransi tingkat nyeri yang dirasakan. Tabel 2 dan Tabel 3 memperlihatkan rerata jumlah obat yang dikonsumsi pada kunjungan II dan kunjungan III.

Pada penelitian ini, adverse event pada subjek diukur untuk setiap kunjungan. Tidak ditemukan adanya perbedaan bermakna antara kedua kelompok pada setiap kunjungan.

Tabel 4 memperlihatkan bahwa hilangnya nyeri pada subjek di kedua kelompok juga dirasakan sebelum subjek melakukan pengukuran pada kunjungan kedua. Kebermaknaan didapatkan pada sebelum kunjungan ketiga. Pada kelompok ekpserimental terdapat 10 subjek $(76,9 \%)$ dan pada kelompok pembanding terdapat tiga subjek $(23,1 \%)$ dengan nilai $\mathrm{p}<0,05$.

Tabel 2. Rescue medication kunjungan II

\begin{tabular}{clcc}
\hline \multicolumn{2}{c}{ Rescue medication } & Mean \pm SD & p \\
\hline \multirow{2}{*}{ Dikonsumsi } & Kelompok $1 \mathrm{n}=48$ & $5,25 \pm 4,37$ & 0,610 \\
& Kelompok 2 $\mathrm{n}=43$ & $5,81 \pm 4,30$ & \\
Sisa & Kelompok $1 \mathrm{n}=48$ & $4,75 \pm 4,37$ & 0,610 \\
& Kelompok 2 $\mathrm{n}=43$ & $4,19 \pm 4,30$ & \\
\hline
\end{tabular}

Ket: Kelompok 1 (Eperison + Ibuprofen); Kelompok 2 (Ibuprofen)

Tabel 3. Rescue medication kunjungan III

\begin{tabular}{clcc}
\hline \multicolumn{2}{c}{ Rescue medication } & Mean \pm SD & p \\
\hline \multirow{2}{*}{ Dikonsumsi } & Kelompok 1 $\mathrm{n}=29$ & $6,00 \pm 3,85$ & 0,836 \\
& Kelompok 2 $\mathrm{n}=30$ & $6,13 \pm 3,52$ & \\
\multirow{2}{*}{ Sisa } & Kelompok 1 n=29 & $4,00 \pm 3,85$ & 0,836 \\
& Kelompok 2 n=30 & $3,83 \pm 3,52$ & \\
\hline
\end{tabular}

Ket: Kelompok 1 (Eperisone + Ibuprofen); Kelompok 2 (Ibuprofen) 
Pada penelitian ini, subjek juga diukur status fungsionalnya menggunakan FFD test yang dilakukan pada setiap kunjungan. Tabel 5 memperlihatkan bahwa kedua kelompok pada kunjungan II dan III menunjukkan adanya perbaikan status fungsional bila dibandingkan pada kunjungan I namun hasil statistik tidak menunjukkan adanya perbedaan bermakna antara kedua kelompok. Pada kunjungan kedua, kelompok eksperimental memiliki jumlah subjek yang lebih banyak yang mampu melakukan FFD test dengan jarak $<10 \mathrm{~cm}$ yakni sebesar 30 subjek $(62,5 \%)$ dibandingkan kelompok pemban- ding sebesar 24 subjek $(55,8 \%)$.

Perbandingan perbaikan status fungsional juga dilakukan pada setiap kelompok sebelum dan sesudah pengobatan. Hasil analisis menunjukkan adanya perbaikan yang bermakna pada masing-masing kelompok di setiap kunjungan dengan membandingkan antara kunjungan I dengan kunjungan II (Tabel 6), kunjungan I dengan kunjungan III (Tabel 7) masing-masing dengan nilai $\mathrm{p}<0,05$, sedangkan antara kunjungan II dan III tidak menunjukkan adanya kebermaknaan dengan nilai $\mathrm{p}>0,05$ (Tabel 8).

Tabel 4. Hilangnya rasa nyeri

\begin{tabular}{lcccccc}
\hline & $\begin{array}{c}\text { Nyeri hilang sebelum } \\
\text { kunjungn II }\end{array}$ & $\%$ & $\mathbf{p}$ & $\begin{array}{c}\text { Nyeri hilang sebelum } \\
\text { kunjungan III }\end{array}$ & \% & p \\
\hline Kelompok 1 & 11 & 57,9 & 0,613 & 10 & 76,9 & 0,023 \\
Kelompok 2 & 8 & 42,1 & & 3 & 23,1 & \\
\hline
\end{tabular}

Tabel 5. Finger-to-floor distance test (FFD)

\begin{tabular}{|c|c|c|c|c|}
\hline Kelompok & Jarak (cm) & $\mathbf{n}$ & $\%$ & $\mathbf{p}$ \\
\hline \multicolumn{5}{|l|}{ Kunjungan I } \\
\hline \multirow{3}{*}{$\begin{array}{c}\text { Kelompok } 1 \\
(\text { Eperisone }+ \text { Ibuprofen }) \\
(n=54)\end{array}$} & $<10 \mathrm{~cm}$ & 10 & 18,5 & \multirow{8}{*}{0,697} \\
\hline & $10-30 \mathrm{~cm}$ & 27 & 50,0 & \\
\hline & $30-50 \mathrm{~cm}$ & 13 & 24,1 & \\
\hline \multirow{5}{*}{$\begin{array}{l}\text { Kelompok } 2 \\
\text { (Ibuprofen) } \\
\quad(n=46)\end{array}$} & $>50 \mathrm{~cm}$ & 4 & 7,4 & \\
\hline & $<10 \mathrm{~cm}$ & 11 & 23,9 & \\
\hline & $10-30 \mathrm{~cm}$ & 25 & 54,3 & \\
\hline & $30-50 \mathrm{~cm}$ & 7 & 15,2 & \\
\hline & $>50 \mathrm{~cm}$ & 3 & 6,5 & \\
\hline \multicolumn{5}{|l|}{ Kunjungan II } \\
\hline \multirow{4}{*}{$\begin{array}{c}\text { Kelompok 1 } \\
\text { (Eperisone }+ \text { Ibuprofen }) \\
(n=48)\end{array}$} & $<10 \mathrm{~cm}$ & 30 & 62,5 & \multirow{8}{*}{0,488} \\
\hline & $10-30 \mathrm{~cm}$ & 16 & 33,3 & \\
\hline & $30-50 \mathrm{~cm}$ & 2 & 4,2 & \\
\hline & $>50 \mathrm{~cm}$ & 0 & 0 & \\
\hline \multirow{4}{*}{$\begin{array}{l}\text { Kelompok } 2 \\
\text { (Ibuprofen) } \\
(\mathrm{n}=43)\end{array}$} & $<10 \mathrm{~cm}$ & 24 & 55,8 & \\
\hline & $10-30 \mathrm{~cm}$ & 15 & 34,9 & \\
\hline & $30-50 \mathrm{~cm}$ & 2 & 4,7 & \\
\hline & $>50 \mathrm{~cm}$ & 2 & 4,7 & \\
\hline \multicolumn{5}{|l|}{ Kunjungan III } \\
\hline \multirow{3}{*}{$\begin{array}{c}\text { Kelompok } 1 \\
\text { (Eperisone + Ibuprofen }) \\
(\mathrm{n}=29)\end{array}$} & $<10 \mathrm{~cm}$ & 22 & 75,9 & \multirow{8}{*}{0,514} \\
\hline & $10-30 \mathrm{~cm}$ & 6 & 20,7 & \\
\hline & $30-50 \mathrm{~cm}$ & 1 & 3,4 & \\
\hline \multirow{5}{*}{$\begin{array}{l}\text { Kelompok } 2 \\
\text { (Ibuprofen) } \\
\quad(\mathrm{n}=30)\end{array}$} & $>50 \mathrm{~cm}$ & 0 & 0 & \\
\hline & $<10 \mathrm{~cm}$ & 21 & 70,0 & \\
\hline & $10-30 \mathrm{~cm}$ & 8 & 16,7 & \\
\hline & $30-50 \mathrm{~cm}$ & 0 & 0 & \\
\hline & $>50 \mathrm{~cm}$ & 1 & 3,3 & \\
\hline
\end{tabular}


Tabel 6. Perbandingan status fungsional sebelum dan sesudah pengobatan kunjungan I dengan kunjungan II

\begin{tabular}{|c|c|c|c|c|c|c|}
\hline & \multirow{2}{*}{$\begin{array}{c}\text { Jarak } \\
(\mathbf{c m})\end{array}$} & \multicolumn{2}{|c|}{ Kunjungan I } & \multicolumn{2}{|c|}{ Kunjungan II } & \multirow[b]{2}{*}{$\mathbf{p}$} \\
\hline & & $\mathbf{n}$ & $\%$ & $\mathbf{n}$ & $\%$ & \\
\hline \multirow{2}{*}{$\begin{array}{c}\text { Kelompok 1 } \\
\text { (Ibuprofen + Eperison) }\end{array}$} & $<10$ & 10 & 18,5 & 30 & 62,5 & \multirow{2}{*}{0,000} \\
\hline & $>10$ & 44 & 81,5 & 18 & 37,5 & \\
\hline \multirow{2}{*}{$\begin{array}{c}\text { Kelompok II } \\
\text { (Ibuprofen) }\end{array}$} & $<10$ & 11 & 23,9 & 24 & 55,8 & \multirow{2}{*}{0,004} \\
\hline & $>10$ & 35 & 76,1 & 19 & 44,2 & \\
\hline
\end{tabular}

Tabel 7. Perbandingan status fungsional sebelum dan sesudah pengobatan kunjungan I dengan kunjungan III

\begin{tabular}{ccccccc}
\hline & Jarak & \multicolumn{2}{c}{ Kunjungan I } & \multicolumn{2}{c}{ Kunjungan III } & \multirow{2}{*}{ p } \\
& $(\mathbf{c m})$ & $\mathbf{n}$ & $\mathbf{\%}$ & $\mathbf{n}$ & $\mathbf{\%}$ & \multirow{2}{*}{ ( } \\
Kelompok 1 & $<10$ & 10 & 18,5 & 22 & 75,9 & \\
(Ibuprofen + & $10-30$ & 27 & 50,0 & 6 & 20,7 & 0,000 \\
Eperisone) & $30-50$ & 13 & 24,1 & 1 & 3,4 & \\
& $>50$ & 4 & 7,4 & 0 & 0 & \\
Kelompok 2 & $<10$ & 11 & 23,9 & 21 & 70,0 & \\
(Ibuprofen) & $10-30$ & 25 & 54,3 & 8 & 26,7 & 0 \\
& $30-50$ & 7 & 15,2 & 0 & 0 & \\
& $>50$ & 3 & 6,5 & 1 & 3,3 & \\
\hline
\end{tabular}

Tabel 8. Perbandingan status fungsional sebelum dan sesudah pengobatan kunjungan II dengan kunjungan III

\begin{tabular}{ccccccc}
\hline & Jarak & \multicolumn{2}{c}{ Kunjungan II } & \multicolumn{2}{c}{ Kunjungan III } & \multirow{2}{*}{ (cm) } \\
& $\mathbf{n}$ & $\mathbf{\%}$ & $\mathbf{n}$ & $\mathbf{\%}$ & \\
\hline Kelompok 1 & 10 & 30 & 62,5 & 22 & 75,9 & \\
(Ibuprofen + & $10-30$ & 16 & 33,3 & 6 & 20,7 & 0,469 \\
Eperisone) & $30-50$ & 2 & 4,2 & 1 & 3,4 & \\
& $>50$ & 0 & 0 & 0 & 0 & \\
Kelompok II & 10 & 24 & 55,8 & 21 & 70,0 & \\
(Ibuprofen) & $10-30$ & 15 & 34,9 & 8 & 26,7 & 0 \\
& $30-50$ & 2 & 4,7 & 0 & 0 & \\
& $>50$ & 2 & 4,7 & 1 & 3,3 & \\
\hline
\end{tabular}

\section{BAHASAN}

Hasil penelitian ini memperlihatkan bahwa berdasarkan karakteristik dasar didapatkan perempuan lebih banyak mengalami NPB yakni sebesar 61 subjek sedangkan laki-laki sebanyak 39 subjek. Salah satu penyebab perempuan lebih sering mengalami NPB karena adanya degenerasi tulang belakang yang lebih cepat dialami oleh perempuan. Selain itu perempuan memiliki ambang batas persepsi rasa nyeri yang lebih rendah daripada laki-laki. ${ }^{13}$ Rerata usia subjek pada kelompok eksperimental ialah
51,67 sedangkan pada kelompok pembanding ialah 53,96 tahun. Menurut Hoy et al, ${ }^{2}$ insidensi NPB sering terjadi pada pasien dengan usia rerata 50-59 tahun.

Pada setiap kunjungan, intensitas nyeri diukur menggunakan numeric pain scale. Pada kunjungan pertama, rerata nyeri pada kelompok eksperimental sebesar 58,33 \pm 20,25 . Hasil ini tidak jauh berbeda dengan kelompok pembanding, yakni 56,52 $\pm 21,31$. Rerata penurunan nyeri lebih besar pada kelompok eksperimental pada kunjungan kedua dan kunjungan ketiga. Hingga pada 
kunjungan ketiga, rerata intensitas nyeri pada kelompok eksperimen menjadi 20,34 \pm 23,82 , sedangkan pada kelompok pembanding sebesar $28,71 \pm 20,12$. NSAID bekerja dengan cara memblokade konversi asam arakidonat menjadi prostaglandin, sehingga akan mengurangi rasa nyeri yang dirasa$\mathrm{kan}^{14}$ Eperison bekerja secara sentral pada pusat nyeri dan meningkatkan sirkulasi darah sehingga kekakuan otot berkurang. Selain itu, eperison juga memberikan efek antinosiseptif oleh aktivitas blokade pada saluran kalsium. ${ }^{10,15,16}$

Hasil tersebut juga terlihat pada pemulihan nyeri yang hilang pada masing-masing kelompok. Intensitas nyeri yang semakin membaik akan membuat status fungsional pasien semakin membaik. Pada FFD test, subjek pada kelompok eksperimental secara bermakna lebih unggul dalam perbaikan status fungsionalnya dibandingkan kelompok pembanding di kunjungan II dan III saat dibandingkan dengan kunjungan pertama/ baseline. Hasil ini menunjukkan kombinasi ibuprofen dan eperison lebih baik dalam meningkatkan status fungsional subjek dengan NPB akut non-spesifik.

\section{SIMPULAN}

Status fungsional pada pasien nyeri punggung bawah akut non-spesifik yang diberikan pengobatan terapi kombinasi ibuprofen dan eperison lebih baik daripada pengobatan dengan ibuprofen saja.

\section{Konflik Kepentingan}

Penulis menyatakan bahwa tidak terdapat konflik kepentingan dalam studi ini.

\section{DAFTAR PUSTAKA}

1. Allegri M, Montella S, Salici F, Valente A, Marchesini M, Compagnone C, et al. Mechanisms of low back pain: A guide for diagnosis and therapy [version 1; referees: 3 approved]. F1000Research. 2016;5:1-11.

2. Hoy D, Brooks P, Blyth F, Buchbinder R. The epidemiology of low back pain. Best Pract Res Clin Rheumatol. 2010;24(6): 769-81. Available from: http://dx.doi. org/10.1016/j.berh.2010.10.002

3. Kementerian Kesehatan RI Badan Penelitian dan Pengembangan. Hasil Utama Riset Kesehatan Dasar. Kementrian Kesehat Republik Indones [Internet]. 2018;1100. Available from: http://www. depkes.go.id/resources/download/infoterkini/hasil-riskesdas-2018.pdf

4. Wulandari RA, J Maja PS, Khosama H. Gambaran faktor yang mempengaruhi nyeri punggung bawah pada buruh kapal. eCliniC. 2014;2(1):2.

5. Tsekoura M, Koufogianni A, Billis E, Tsepis E. Work-related musculoskeletal disorder among female and male nursing personnel in Greece. World Journal of Research and Review (WJRR). 2017;3(1):8-15.

6. Arwinno LD. Keluhan nyeri punggung bawah pada penjahit garmen. HIGEIA (Journal of Public Health Research and Development). 2018;2(3):406-16.

7. Piccoliori G, Engl A, Gatterer D, Sessa E, In Der Schmitten J, Abholz HH. Management of low back pain in general practice - is it of acceptable quality: an observational study among 25 general practices in South Tyrol (Italy). BMC Fam Pract. 2013;14.

8. Widyantanti MAS, Pinzon RT. Penggunaan eperisone hydrocloride untuk mengurangi nyeri pasien nyeri punggung bawah akut di Rumah Sakit Bethesda Yogyakarta, Media Farmasi 2017;14(2): 177-92.

9. Pinzon RT, Sanyasi RDLR. Systematic Review of eperisone for low back pain. Asian J Pharm Pharmacol. 2018;4(2):140-6.

10. Rusinyol FC, Pericé RV, Boronat ER, Bosch FF. Effects of two different doses of eperisone in the treatment of acute low back pain. J Appl Res. 2009;9(1-2):23-9.

11. Haywood KL, Garratt AM, Jordan K, Dziedzic K, Dawes PT. Spinal mobility in ankylosing spondylitis: reliability, validity, and responsiveness, Rheumatology (Oxford). 2004;43(6):750-7. Doi: 10.1093/rheumatology/keh169. Epub 2004 Apr 7.

12. Carregoaro RL, Silva LCCB, Gil Coury HJC. Comparison between two clinical test for the evaluation of posterior thigh muscle flexibility. Braz. J. Phys. Ther. 2007;11(2):125-30.

13. Wáng YXJ, Wáng JQ, Káplár Z. Increased low back pain prevalence in females than in males after menopause age: Evidences based on synthetic literature review. 
Quant Imaging Med Surg. 2016;6(2): 199-206.

14. Kuritzky L, Samraj GP. Nonsteroidal antiinflammatory drugs in the treatment of low back pain. J Pain Res. 2012;5:57990.

15. Khan AF, Parveen K, Khan AS. Efficacy and tolerability of eperisone versus tizanidine in patients suffering from low back pain with muscle spasm. Int J Res Med Sci. 2017;5(6):2694.

16. Melilli B, Piazza C, Vitale DC, Marano MR, Pecori A, Mattana P, et al. Human pharmacokinetics of the muscle relaxant, eperisone hydrochloride by liquid chromatography-electrospray tandem mass spectrometry. Eur J Drug Metab Pharmacokinet. 2011;36(2):71-8. 